\title{
A novel cucumber gene associated with systemic acquired resistance
}

\author{
Vipaporn Phuntumart*, Pascal Marro, Jean-Pierre Métraux, Liliane Sticher \\ Department of Biology, Plant Biology, University of Fribourg, $10 \mathrm{ch}$. du Musée, 1700 Fribourg, Switzerland
}

\begin{abstract}
Several genes were isolated by differential display of mRNAs from cucumber leaves inoculated with the bacterium, Pseudomonas syringae pv. lachrymans. A full-length cDNA encoding a novel pathogen-induced gene, Cupi4, was cloned and characterized in detail. While Cupi4 did not share evident homology with known sequences in the database at the nucleotide level, the predicted amino acid sequence of $C u p i 4$ shared homology with the pathogen-inducible proteins, pMB57-10G 5' of Brassica napus (21\%) and CXc750/ESC1 of Arabidopsis thaliana (16\%). Cupi4 transcripts accumulated after $12 \mathrm{~h}$ in leaves inoculated with $P$. s. lachrymans and after $48 \mathrm{~h}$ in the systemic upper leaves of the inoculated plants. Treatment with the chemical inducers of systemic acquired resistance (SAR), salicylic acid, 2,6-dichloroisonicotinic acid and benzothiadiazole as well as inoculation with different pathogens, P. s. syringae, Colletotrichum lagenarium and tobacco necrosis virus also led to the accumulation of Cupi4 transcripts. The increase of Cupi4 transcripts in both the inoculated first leaf and in systemic upper leaves suggested that the Cupi4 gene product is associated with systemic acquired resistance in cucumber. Induced expression of CUPI4 in different host strains of a bacterium, Escherichia coli, led to death of bacterial host cells, suggesting that CUPI4 might have antibacterial properties.
\end{abstract}

Keywords: Class III chitinase; Cucumber; Cupi4; Pseudomonas syringae pv. lachrymans; Pathogen-induced proteins; Systemic acquired resistance

\section{Introduction}

Application of a necrotizing pathogen or a chemical inducer to plants can result in a defense mechanism called systemic acquired resistance (SAR). It is a form of resistance that involves a local, hypersensitive response, as well as in protection of tissues distant from the site of first inoculation to a subsequent infection by the same and/or different pathogens. SAR usually exhibits a broad range resistance and provides long lasting protection [1-4]. Activation of inducible defenses depends upon recognition of the invading pathogen via a number of signal transduction pathways. Several signal molecules, including salicylic acid (SA), jasmonic acid (JA) and ethylene, have been identified. In Arabidopsis, a regulatory protein, NPRI has been implicated as a requirement for both SAR and induced systemic resistance. It mediates

The nucleotide sequence data reported will appear in the DDBJ/EMBL/ GenBank Nucleotide Sequence Database under the accession no. DQ482461.

* Corresponding author. Present Address: Department of Biological Sciences, Bowling Green State University, Bowling Green, OH 43403, USA.

Tel.: +1 419372 4097; fax: +1 4193722024 .

E-mail address: vphuntu@bgsu.edu (V. Phuntumart). cross-talk between salicylic acid and jasmonic acid signaling pathways [5-8]. A number of mutants compromised in their ability to be induced to the SAR state have been documented in Arabidopsis [1,9]. During SAR, new proteins called pathogenesis-related (PR) proteins accumulate in infected tissues as well as uninfected systemic tissues $[1-4,10]$. Several chemicals including salicylic acid (SA), arachidonic acid, 2,6-dichloroisonicotinic acid (INA) and benzo(1,2,3)thiadiazole-7-carbothionic acid $S$-methyl ester (BTH) are known as inducible substances for SAR, and their application leads to the expression of the same set of SAR genes as inoculation with pathogens [11-14].

Tobacco (Nicotiana tabacum), cucumber (Cucumis sativus) and Arabidopsis have been used as models for understanding host-pathogen interactions of the SAR [1-4]. In cucumber, induction of SAR by different pathogens as well as by SA, INA or BTH has been reported [15-20]. Infection of young cucumber plants with different pathogens can lead to broad spectrum SAR to at least 13 diseases and can protect plants from several pathogens for 4-6 weeks [21]. An increased level of chitinase, peroxidase, $\beta$-1,3-glucanase and lipoxygenase both in local and systemic tissues after inoculation with Colletotrichum lagenarium, tobacco necrosis virus (TNV), 
Pseudomonas syringae pv. syringae or P. s. lachrymans has been documented [19,22-26]. Among these proteins, cucumber class III chitinase has been used as a marker for SAR in cucumber because its expression is very low or undetectable in control tissues and is increased strongly in inoculated as well as systemic tissues after inoculation with TNV, and after treatment with SA, INA or BTH [23,27-29]. In this work, we used mRNA differential display to isolate novel genes that are expressed strongly during acquired resistance in cucumber induced by $P$. s. lachrymans. We isolated several novel cDNAs and one of them, cucumber pathogen-induced 4 (Cupi4), was characterized. Cupi4 transcripts accumulated locally and systemically after inoculation with several pathogens and after treatment with SA, INA or BTH. These results support the hypothesis that Cupi4 is associated with SAR in cucumber.

\section{Materials and methods}

\subsection{Plant materials, treatment with different pathogens, chemical inducers of SAR and wounding}

Cucumber plants (C. sativus L., cv. Wisconsin SMR-58) were grown in a greenhouse with a 14-h photoperiod. The first leaves were inoculated at 10 sites per leaf with $P$. s. lachrymans or $P$. s. syringae at a concentration of $2 \times 10^{8}$ cells $/ \mathrm{ml}(\mathrm{A} 260=$ 0.075) using a needleless syringe. Control plants were treated with water. Five microliters droplets of the spore suspension $\left(2 \times 10^{5}\right.$ spores $\left./ \mathrm{ml}\right)$ of $C$. lagenarium were applied on the first leaves of cucumber plants. Plants treated with water were used as controls. For TNV treatment, one TNV-inoculated cotyledon of cucumber was ground in $2 \mathrm{ml}$ of water, the homogenate was filtered through two layers of Miracloth and $10 \mathrm{mg}$ of celite was added. The first leaves of cucumber plants were gently rubbed with the suspension of TNV particles and celite. Plants treated with the mixture of celite and water were used as controls.

One millimolar of SA, INA and BTH were applied by soildrench application. As a control for SA, or INA and BTH treatment, plants were treated, respectively, with water or wetting powder. For wounding, the first leaves were squeezed with flat-bladed pliers at six different sites.

\subsection{RNA extraction and $m R N A$ differential display}

The first leaves of cucumber plants grown in the greenhouse were inoculated on the border with the bacterial pathogen, $P$. $s$. lachrymans as described above and the inoculation with water was used as control. RNA from the middle non-inoculated area was isolated from duplicates of control and inoculated leaves $48 \mathrm{~h}$ after inoculation. For RNA isolation, $0.5-3 \mathrm{~g}$ of leaf material was ground in liquid nitrogen with a mortar and pestle. The ground powder was added to $8 \mathrm{ml}$ of a $1: 1(\mathrm{v} / \mathrm{v})$ mixture of phenol-chloroform-isoamyl alcohol and $2 \times$ NETS buffer (200 mM NaCl, 2 mM Na 2 EDTA, 20 mM Tris-HCl pH 7.5, $1 \%$ (w/v) SDS). The slurry was vortexed vigorously, centrifuged and the upper phase was extracted twice with $4 \mathrm{ml}$ chloroform. The RNA was precipitated by mixing the upper aqueous phase with an equal volume of $6 \mathrm{M} \mathrm{LiCl}$ for $16 \mathrm{~h}$ at $4{ }^{\circ} \mathrm{C}$. After centrifugation at $10,000 \times g$, the RNA pellet was resuspended by adding 0.1 volume of $3 \mathrm{M}$ sodium acetate $\mathrm{pH} 5.2$ and 2.5 volume of ethanol. After centrifugation, the RNA pellet was resuspended in TE buffer pH 8 (10 mM Tris-Cl, $1 \mathrm{mM}$ EDTA), and was quantified by UV spectrophotometer and the solution was treated with RNase-free DNaseI (Boehringer) following manufacturer's instructions. mRNA differential display was performed according to Liang et al. [30] and Liang and Pardee [31]. The differentially expressed cDNAs were cloned in pBluescript vector (Stratagene) and were analyzed further.

\subsection{RNA gel blot analysis}

RNA samples (10 $\mu \mathrm{g} / \mathrm{lane})$ were separated on a $1 \%$ agarose gel containing formaldehyde [32] and were transferred for $16 \mathrm{~h}$ to a Hybond-N nylon membrane (Amersham) according to the manufacturer's instructions. The membrane was then air-dried and the RNA was cross-linked to the membrane with UV light $(312 \mathrm{~nm})$ for $3 \mathrm{~min}$. Prehybridization was performed in a prehybridization solution $(0.5 \mathrm{M}$ phosphate buffer $\mathrm{pH} 7.2 / 7 \%$ $\mathrm{SDS} / 1 \%$ bovine serum albumin) for $2 \mathrm{~h}$ at $65{ }^{\circ} \mathrm{C}$, followed by hybridization in the same buffer overnight at $65^{\circ} \mathrm{C}$. The membrane was washed twice in $0.2 \times \mathrm{SSC}(0.15 \mathrm{M} \mathrm{NaCl} /$ $0.015 \mathrm{M} \mathrm{Na}_{3}$ citrate) $/ 0.1 \% \mathrm{SDS}$ at $65^{\circ} \mathrm{C}$ and exposed to an X-OMAT AR film (Kodak). The probes were radiolabelled with $\alpha-{ }^{32}$ P-dATP using the RadPrime DNA labeling system (GibcoBRL).

\subsection{Screening of a cDNA library from infected plants}

The single-stranded cDNA isolated by differential display was used as a probe to isolate the full-length cDNA in a $\lambda$ ZAP cDNA library [32,33] made from systemic second leaves of cucumber plants which were infected on the first leaf with $P$. $s$. syringae (kindly provided by Dr. Ray Hammerschmidt, Michigan State University, East Lansing, MI, USA). Three plaque lifts per plate were performed on reinforced nylon membranes (Schleicher \& Schuell, Germany). Prehybridization and hybridization were carried out under high stringency at $65{ }^{\circ} \mathrm{C}$, under the same conditions as described for the RNA gel blot analysis. The Exassist helper phage (Stratagene) was used for in vivo excision of cDNAs from phage to pBluescript plasmid, following the manufacturer's instructions.

\subsection{Genomic DNA gel blot analysis}

Genomic DNA was extracted from leaves of cucumber and Arabidopsis plants as described [34]. A $10-\mu \mathrm{g}$ portion of DNA was digested with the restriction enzymes, BamHI, HindIII, EcoRI, or EcoRV. Digested genomic DNA was subjected to electrophoresis on a $1 \%$ agarose gel. The gel was then depurinated in $0.25 \mathrm{~N} \mathrm{HCl}$ for $15 \mathrm{~min}$, denatured in $0.5 \mathrm{~N} \mathrm{NaOH} /$ $1.5 \mathrm{M} \mathrm{NaCl}$ for $30 \mathrm{~min}$, neutralized in $0.5 \mathrm{M}$ Tris- $\mathrm{HCl}(\mathrm{pH}$ 8.0)/1.5 M NaCl for $30 \mathrm{~min}$, and blotted for $16 \mathrm{~h}$ to a Hybond-N nylon membrane (Amersham) according to the manufacturer's instructions. The DNA was cross-linked to the membrane with UV light $(312 \mathrm{~nm})$ for $3 \mathrm{~min}$. The $\alpha-{ }^{32} \mathrm{P}-\mathrm{dATP}$ radiolabelled 
probe was generated using the RadPrime DNA labeling system (Gibco-BRL). Hybridization was carried out overnight at both high $\left(65^{\circ} \mathrm{C}\right)$ and low $\left(50{ }^{\circ} \mathrm{C}\right)$ stringency. Washing steps were done twice with $0.2 \times \mathrm{SSC} / 0.1 \% \mathrm{SDS}$, at 65 and $50{ }^{\circ} \mathrm{C}$ for high and low stringency, respectively. The membrane was exposed to an X-OMAT AR film (Kodak).

\subsection{Overexpression of Cupi4 cDNA in Escherichia coli}

To limit potential toxic effects of Cupi4 in E. coli, the sequence encoding for mature Cupi4 without signal peptide was cloned into an isopropylthiogalactoside (IPTG)-inducible expression plasmid, pQE30 (Qiagen, CA). The 5'forward primer was designed with an in-frame BamHI site (underlined), GTGGGATCCCGGCCTTATTACTTG and the 3 'reverse primer incorporated a PstI site (underlined), CGCTGCAGGACGACAACACACC. PCR conditions were as follows: 30 cycles with the following steps: $94{ }^{\circ} \mathrm{C}$ for $30 \mathrm{~s}, 50{ }^{\circ} \mathrm{C}$ for $2 \mathrm{~min}, 72{ }^{\circ} \mathrm{C}$ for 2 min and ended with an additional extension step at $72{ }^{\circ} \mathrm{C}$ for $5 \mathrm{~min}$. The PCR product was subcloned into the same restriction sites in the $E$. coli expression vector pQE30, to generate the amino-terminal six-histidine (6xHis)-tag recombinant protein. The resulting plasmid, pQE30-Cupi4 was selected and transformed into moderate expression $E$. coli host strains M15 (Qiagen, CA) or BL21(DE3) (Novagen, WI), or into a high-stringency expression host strain BL21(DE3)pLysS (Novagen, WI) via electroporation according to Sambrook et al. [32]. The purified plasmid pQE30-Cupi4 was sequenced to confirm an in-frame insertion. Expression and purification of the recombinant protein were performed according to the manufacturer's instructions (Qiagen, CA). Briefly, the E. coli strains carrying plasmid pQE30-Cupi4 were grown in $500 \mathrm{ml}$ of LB medium containing $100 \mathrm{mg} / \mathrm{ml}$ ampicillin at 30 or $37^{\circ} \mathrm{C}$ on a platform shaker rotating at $220 \mathrm{rpm}$. When the absorbance at $600 \mathrm{~nm}$ for each culture reached $0.5-0.7$, the cultures were induced with 0.5 or $1 \mathrm{mM}$ IPTG and grown for an additional $8 \mathrm{~h}$. The growth rate of the bacteria was measured with a spectrophotometer at the absorbance of $600 \mathrm{~nm}$ before induction and every hour after induction for an additional $8 \mathrm{~h}$.

\section{Results}

\subsection{Identification and analysis of pathogen-induced cDNA fragments isolated by $m R N A$ differential display}

mRNA differential display was used to compare the expression of genes in the center of leaves inoculated on the border with $P$. s. lachrymans and in water-treated leaves. Fourteen bands that were differentially expressed were excised and amplified by polymerase chain reaction (PCR). The PCR products were cloned in the $\mathrm{pBluescript}$ plasmid. Twelve clones were collected for each band giving 168 clones in total [29]. The 168 cDNAs were used as probes for RNA gel blot analysis to confirm the differential expression of mRNAs after pathogen inoculation. Fourteen clones showed differential expression in leaves inoculated with $P$. s. lachrymans (Fig. 1). These 14 cDNA clones named Did-1 to Did-14 were sequenced and analyzed with the Basic Local Alignment Research Tool (BLAST) accessed through Internet at the site of the National Center for Biotechnology Information, NCBI (http:// www.ncbi.nih.gov/BLAST/) [35] and with the Pedro's BioMolecular Research Tools (http://www.public.iastate.edu/ $\sim$ pedro/research_tools.html). Marro [29] discovered that the Did-2 sequence (136 bp) was identical to cucumber class III chitinase CUSCHI (GenBank accession no. AAA33120) [23]. The sequence of Did-3 (147 bp) [29], Did-5 (237 bp), Did-6 (393 bp) and Did-7 (312 bp) were identical to a cucumber ethylene-induced peroxidase, CuPer 2 (GenBank accession no. AAA33121) [36]. The Did-8 sequence (343 bp) was $66 \%$ homologous to an Arabidopsis peroxidase, prxr5 (GenBank accession no. CAA66961) [37]. The sequence of Did-13 (189 bp) showed $45 \%$ identity to the F-box family protein of Arabidopsis (GenBank accession no. NM_120479). Several cDNAs including Did-1 (311 bp, found by Marro [29]), Did-4 (146 bp), Did-9 (94 bp), Did-10 (106 bp), Did-11 (102 bp), Did-12 (148 bp), and Did-14 (112 bp) did not share any significant similarity with known sequences in databases using BLAST programs. The partial cDNA called Did-1 and Did-4 were further characterized because these two cDNAs were strongly expressed and exhibited a unique hybridization pattern on the RNA gel blot (Fig. 1). In this work, we focus only on the expression of Did-4. Did-1 has been studied extensively by Marro [29].

\subsection{Isolation of a full-length cDNA and sequence analysis of Cupi4}

The Did-4 cDNA fragment was used as a probe to isolate the corresponding full-length cDNA from a cDNA library made from systemic leaves of cucumber plants infected with $P$. s. syringae. The full-length cDNA of $649 \mathrm{bp}$ was obtained and called Cupi4 (cucumber pathogen-induced 4). Analysis of the sequence of the Cupi4 cDNA showed that it contains a 25-bp long untranslated leader sequence followed by an open reading frame coding for a 87 -amino acid-long protein with a putative signal peptide. A consensus polyadenylation site (AATAAA [38]) is present at $36 \mathrm{bp}$ downstream from the stop codon in the $3^{\prime}$ untranslated region but the poly (A) tail is absent. To confirm that Cupi4 is a full length cDNA with no poly (A) tail, rapid amplification of cDNA ends (RACE) of both the $5^{\prime}$ and $3^{\prime}$ ends was performed with a 5/3 RACE Kit (Boehringer Mannheim, Mannheim, Germany) according to the manufacturer's instructions. No poly(A) was detected at the $3^{\prime}$ end of the Cupi4 mRNA (data not shown). In addition, RNA gel blot analysis using total RNA from leaves inoculated with $P$. s. lachrymans was used to estimate the size of the Cupi4cDNA in comparison to the RNA ladder (Gibco-BRL) as a standard marker. The RNA blots were hybridized with either Did4 (84-230 bp fragment of Cupi4cDNA) or full length Cupi4 cDNA as a probe. The hybridized bands of both probes had a calculated size of approximately $652 \mathrm{bp}$ (data not shown). These results suggested that Cupi4 is a near full length cDNA and it does not contain poly (A) tail at $3^{\prime}$ UTR. 


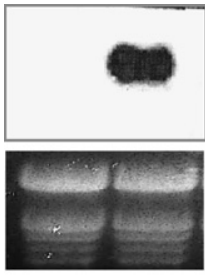

Did-1
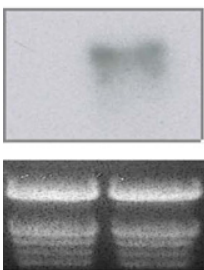

Did-6

(Cuper2)
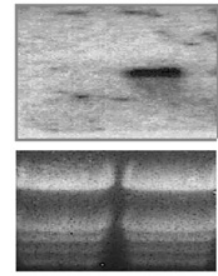

Did-2 (chitinase)
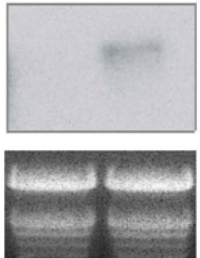

Did-7

(Cuper2)
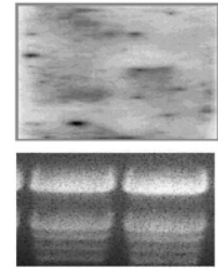

Did-3

(Cuper2)
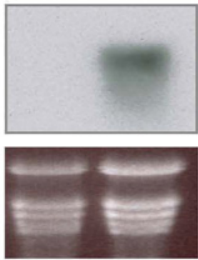

Did-8 (peroxidase)
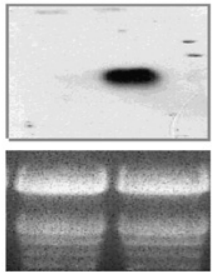

Did-4
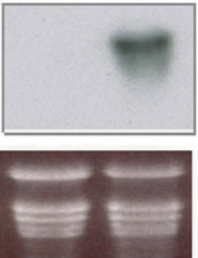

Did-9

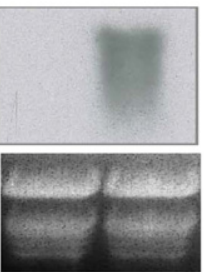

Did-13

(F-box)
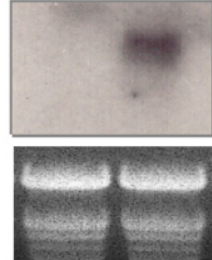

Did-5

(Cuper2)

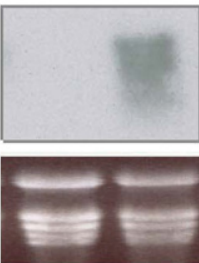

Did-10

(Cuper2)

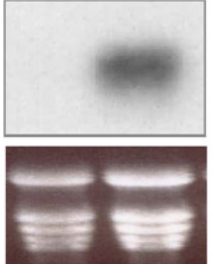

Did-11

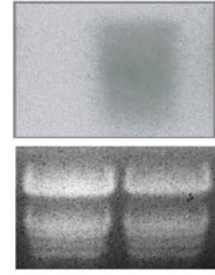

Did-12

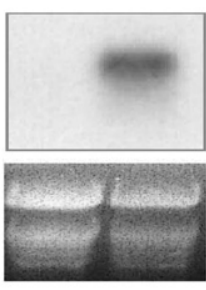

Did-14

Fig. 1. RNA gel blot analysis of differential pathogen-induced mRNAs. Total RNA from control leaves treated with water (C) or inoculated leaves treated with $P$. $s$ lachrymans (I) was isolated $48 \mathrm{~h}$ after inoculation. Each lane contains $10 \mu \mathrm{g}$ of RNA and was hybridized with the indicated radiolabelled cDNA probes isolated from PCR mRNA differential display. Ethidium bromide staining served as control for an equal loading.

The prediction of CUPI4 localization using PSORT (Predict Protein Sorting Signals Coded in Amino Acid Sequences, at GenomeNet, Japan, http://psort.ims.u-tokyo.ac.jp/form.html) and SignalP 3.0, using neural networks $(\mathrm{NN})$ and hidden
Markov models (HMM) trained on eukaryotes [39] shows that CUPI4 might be targeted either to the vacuole (83\%) or outside the cells $(82 \%)$. Hydropathy analysis of the amino acid sequence using the Kyte-Doolittle scale combined with
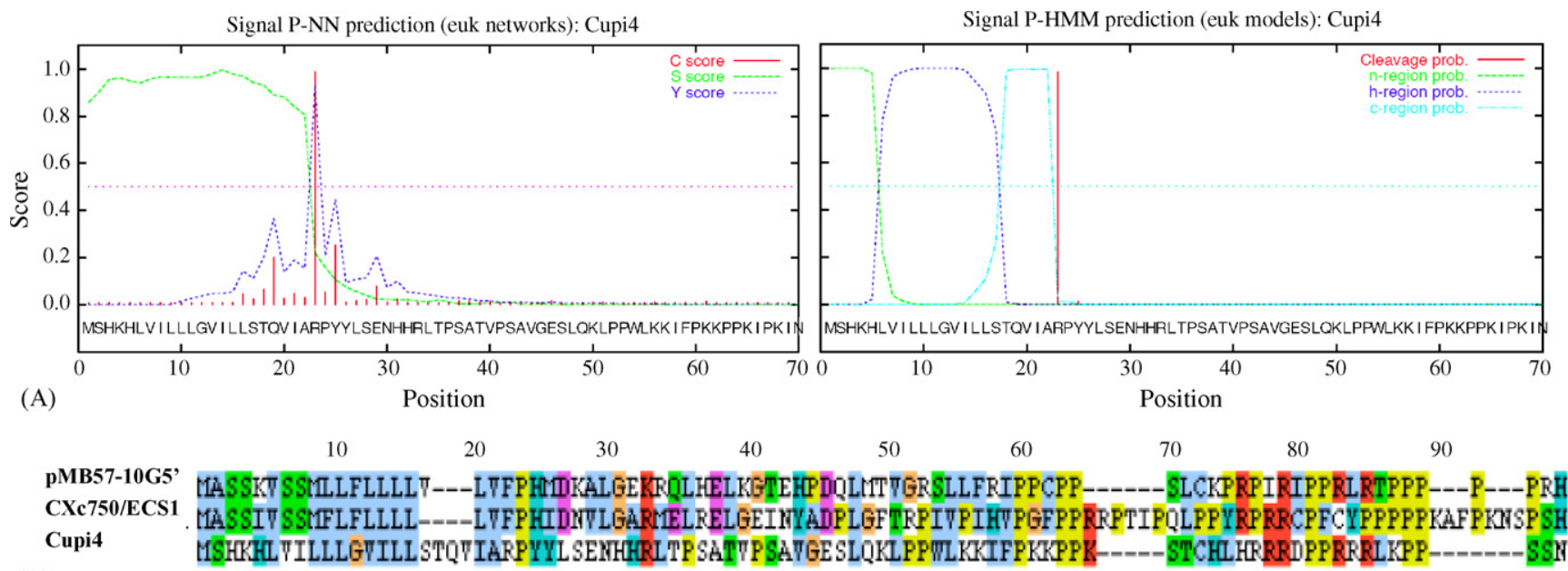

(B)

Fig. 2. (A) The graphical output for prediction of protein sorting signals and localization sites in amino acid sequences (PSORT) of CUPI4 by SignalP 3.0 . The left panel derived from the neural network and the right panel derived from the hidden Markov model. In the left panel, C-score is the cleavage site score, S-score indicates the length of predicted signal peptide Y-score derived from the combination of C-score and S-score. In the right panel, a signal peptide is given by the position of the $\mathrm{h}$ region, the cleavage site was assigned by the scores of the $\mathrm{n}-\mathrm{h}$ - and c-regions of the signal peptide. (B) Sequences alignment of the deduced amino acids of pMB5710G $5^{\prime}$ (GenBank accession no. AI352744), CXc750/ECS1 5' (GenBank accession no. X72022), and CUPI4 (GenBank accession no. DQ482461). 


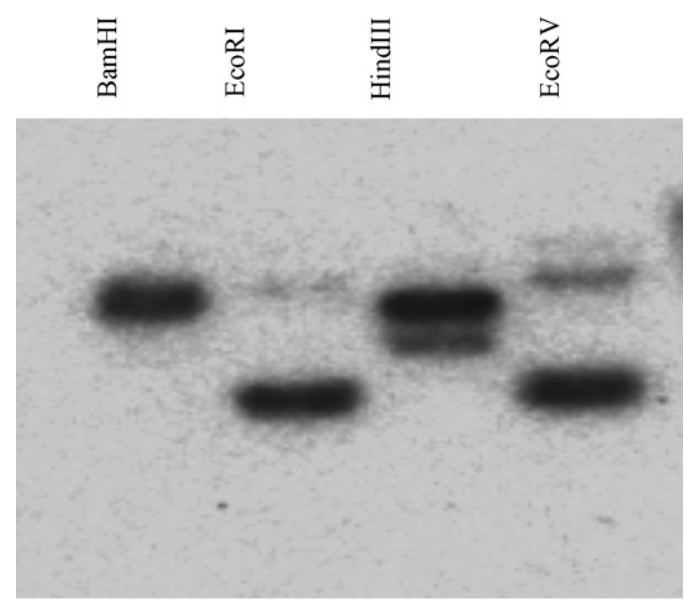

Fig. 3. Southern analysis of genomic DNA extracted from cucumber plants. DNA was digested with different restriction enzymes. Hybridization was performed under high stringency $\left(65^{\circ} \mathrm{C}\right)$ with the Cupi4 cDNA as a probe.

hydrophobic moment and TMS prediction (http://www.tcdb.org/ analyze.php) indicated that the protein is highly hydrophilic except for the $\mathrm{N}$-terminal part that has the features of a potential signal sequence for translocation in the endoplasmic reticulum. The putative signal sequence comprises 23 amino acids and includes a positively charged amino terminal sequence followed by a central hydrophobic region and a more polar carboxyl terminal region. The predicted cleavage site of the signal peptide is between Ala-22 and Arg-23 (Fig. 2A). The mature form of the protein has a calculated molecular mass of $7391 \mathrm{Da}$ and a calculated pI of 11.65. Analysis of the amino acid sequence of

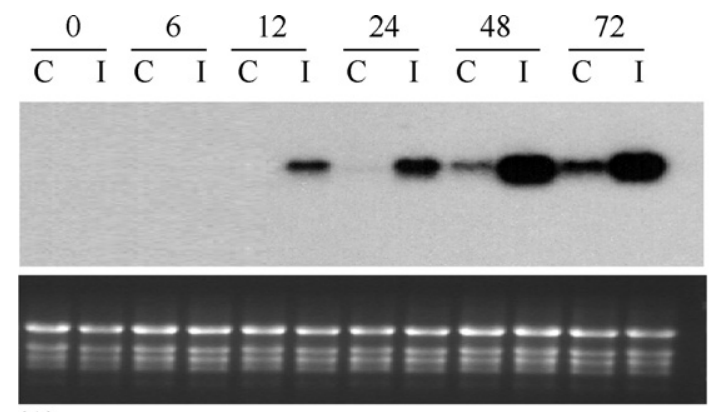

(A)

Cupi4
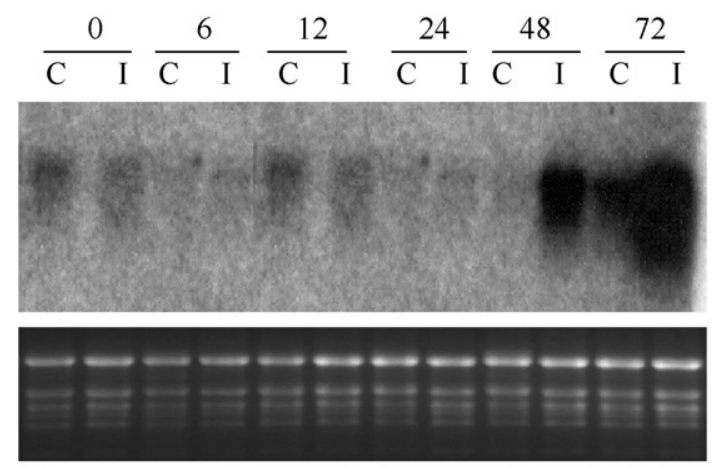

(C)

Chitinase
CUPI4 using ClustalW (http://www.ebi.ac.uk/clustalw/ index.html [40]), showed that CUPI4 was $21 \%$ homologous and $44 \%$ identical to Brassica napus pMB57-10G 5' (GenBank accession no. AI352744) [41] and was 16\% homologous and 44\% identical to Arabidopsis CXc750/ECS1 (GenBank accession no. X72022) $[42,43]$. The alignment of the sequences of these three proteins is shown in Fig. $2 \mathrm{~B}$.

\subsection{Southern analysis of the cucumber genomic DNA}

To estimate the number of Cupi4-related genes in cucumber, Southern blot analysis was performed with the Cupi4 cDNA as a probe (Fig. 3). The enzymes used in this study were HindIII, which recognizes a single restriction site in the Cupi4 cDNA at $326 \mathrm{bp}$, and BamHI, EcoRI or EcoRV which do not cut within the sequence. When cucumber genomic DNA was digested with HindIII, Cupi4 hybridized with two fragments. Only one or two fragments were detected when DNA was digested with BamHI, EcoRI and EcoRV. This result indicates that the Cupi4 gene is likely present in a low copy number in the cucumber genome. Southern blot analysis of Arabidopsis genomic DNA with the Cupi4 cDNA as a probe did not show any hybridizing band either at low $\left(50{ }^{\circ} \mathrm{C}\right)$ or high $\left(65^{\circ} \mathrm{C}\right)$ stringency (data not shown).

\subsection{Expression of Cupi4 transcripts at different times after inoculation}

To determine the time-course of accumulation of Cupi4 transcripts in inoculated and uninoculated systemic leaves, total

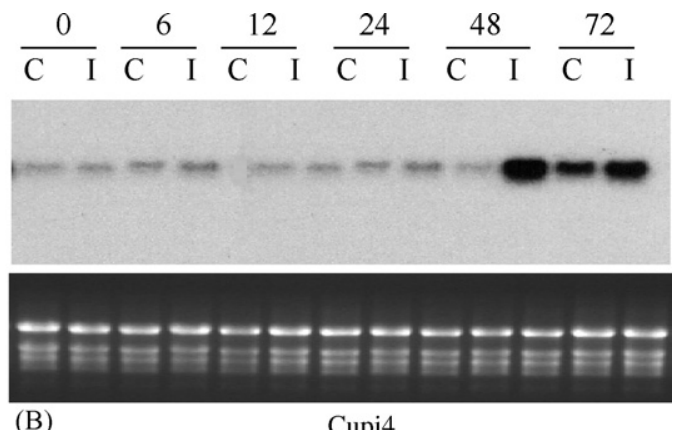

(B) Cupi4
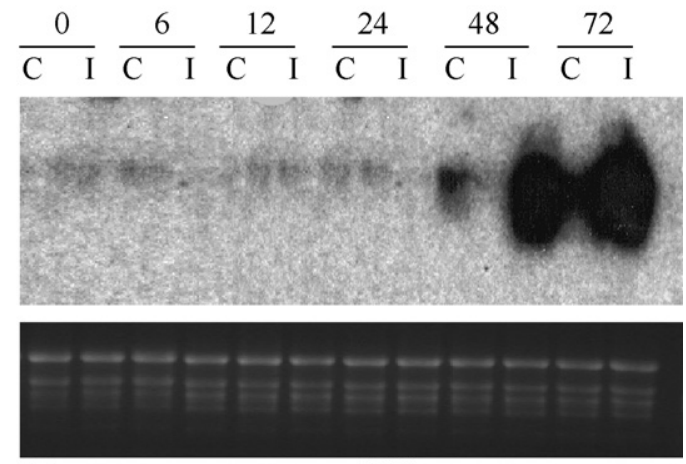

(D)

Chitinase

Fig. 4. Accumulation of Cupi4 (A and B) and cucumber class III chitinase (C and D) transcripts at different times after inoculation with P. s. lachrymans analysed on RNA gel blots. First leaves were inoculated with $P$. s. lachrymans or water as control and RNA was isolated from inoculated first leaves (A and C) or systemic second leaves (B and D) from inoculated (I) or control (C) plants. The numbers indicate the time after inoculation in hours. Each lane contains $10 \mu \mathrm{g}$ of RNA. Ethidium bromide staining served as control for an equal loading. 


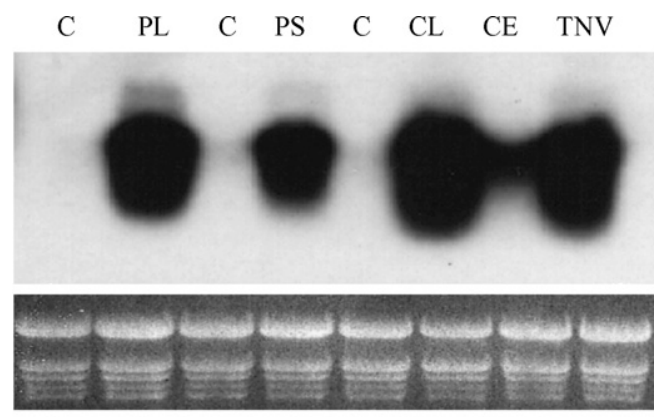

(A)

Cupi4

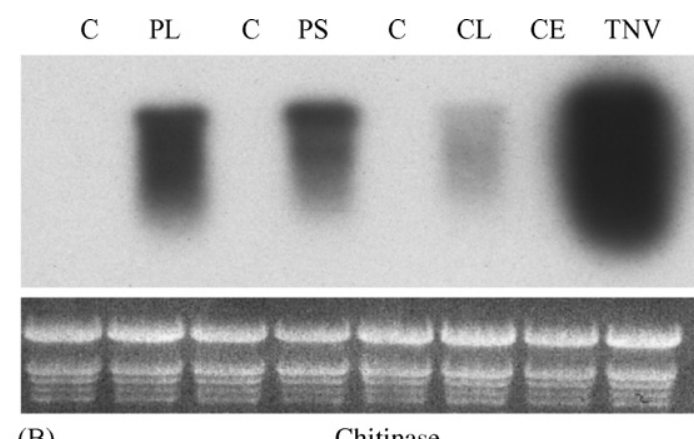

(B)

Chitinase

Fig. 5. Accumulation of Cupi4 (A) and cucumber class III chitinase (B) transcripts after treatment with the different pathogens, P. s. lachrymans (PL), P. s. syringae (PS), C. lagenarium (CL), tobacco necrosis virus (TNV) or water (C) or celite (CE) as controls. Total RNA was extracted from the first leaves 3 days after inoculation. Each lane contains $10 \mu \mathrm{g}$ of RNA. Ethidium bromide staining served as control for an equal loading.

RNA was isolated from first and second leaves of cucumber plants at different time points after inoculation of the first leaves with P. s. lachrymans or water as control. Cupi4 transcripts began to accumulate $12 \mathrm{~h}$ post inoculation (hpi) in inoculated leaves and $48 \mathrm{hpi}$ in systemic upper leaves and were present at a very low level or not detectable in the control leaves. We used cucumber class III chitinase as a marker for SAR in cucumber. In inoculated leaves, chitinase transcripts began to accumulate $24 \mathrm{hpi}$, which is later than the beginning of the expression of Cupi4. In systemic second leaves, the level of chitinase transcripts increased $48 \mathrm{hpi}$ at the same time as the increase of Cupi4 transcripts (Fig. 4).

\subsection{Expression of Cupi4 transcripts in plants treated with} pathogens, wounding and chemical inducers of SAR

To determine if the level of Cupi4 transcripts increased after treatment with different pathogens that induce SAR in cucumber, the first leaf was inoculated with $P$. s. lachrymans, P. s. syringae, C. lagenarium or TNV. Total RNA was extracted from infected leaves 3 days after inoculation and analyzed by RNA blotting. Cupi4 transcripts strongly accumulated after inoculation with these pathogens (Fig. 5A). Similarly, chitinase transcripts also accumulated (Fig. 5B).

The effects of a natural compound, SA, and the synthetic compounds, INA and BTH, which are known inducers of SAR in numerous plant species including cucumber were tested on

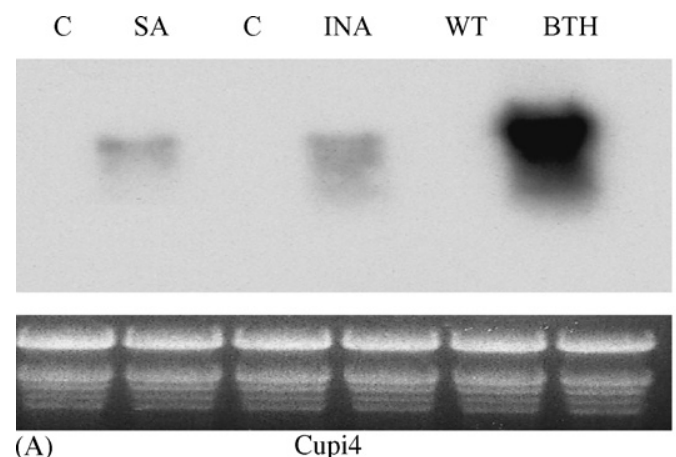

the expression of Cupi4 and chitinase. The levels of Cupi4 and chitinase transcripts were increased after treatment with SA, INA or BTH compared to controls. The levels of both Cupi4 and chitinase transcripts were higher in plants treated with BTH than with INA and SA (Fig. 6). Both Cupi4 and cucumber class III chitinase transcripts were undetectable after wounding (data not shown).

\subsection{Expression of Cupi4 transcripts in different plant tissues}

To study the expression pattern of Cupi4 and chitinase transcripts in different plant tissues, total RNA was isolated from leaves, roots (from plants grown in vitro), fruits, imperfect flowers and perfect flowers. The RNA gel blot showed that the level of Cupi4 transcripts was high in fruits, imperfect flowers, perfect flowers and roots but undetectable in non-inoculated leaves (Fig. 7A). The level of chitinase transcripts was increased only in leaves inoculated with $P$. s. lachrymans (Fig. 7B).

\subsection{In vitro expression of Cupi4}

The growth of bacteria which carried a recombinant plasmid, pQE30-Cupi4 rapidly decreased within the first hour and stopped at $2 \mathrm{~h}$ after IPTG induction compared to the normal growth rate of bacteria from non-induced culture and from the

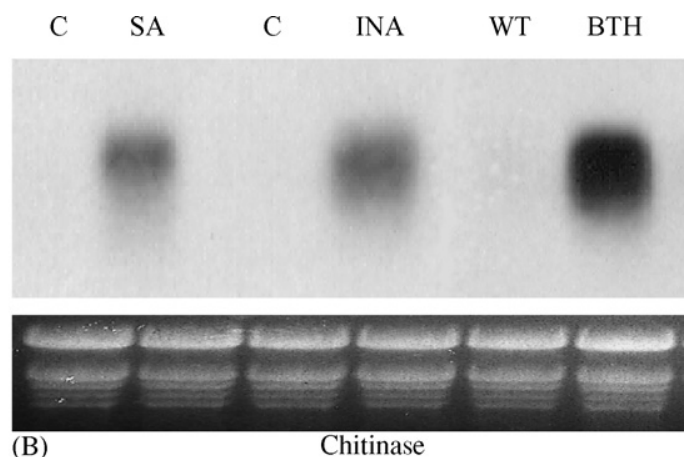

(B)

Fig. 6. Accumulation of Cupi4 (A) and cucumber class III chitinase (B) transcripts after treatment with $1 \mathrm{mM}$ of the SAR inducers; SA, and INA and BTH, or water (C) or wetting powder (WP), respectively, as controls. Total RNA was isolated from first leaves $48 \mathrm{~h}$ after soil drench application. Each lane contains $10 \mu \mathrm{g}$ of RNA. Ethidium bromide staining served as control for an equal loading. 

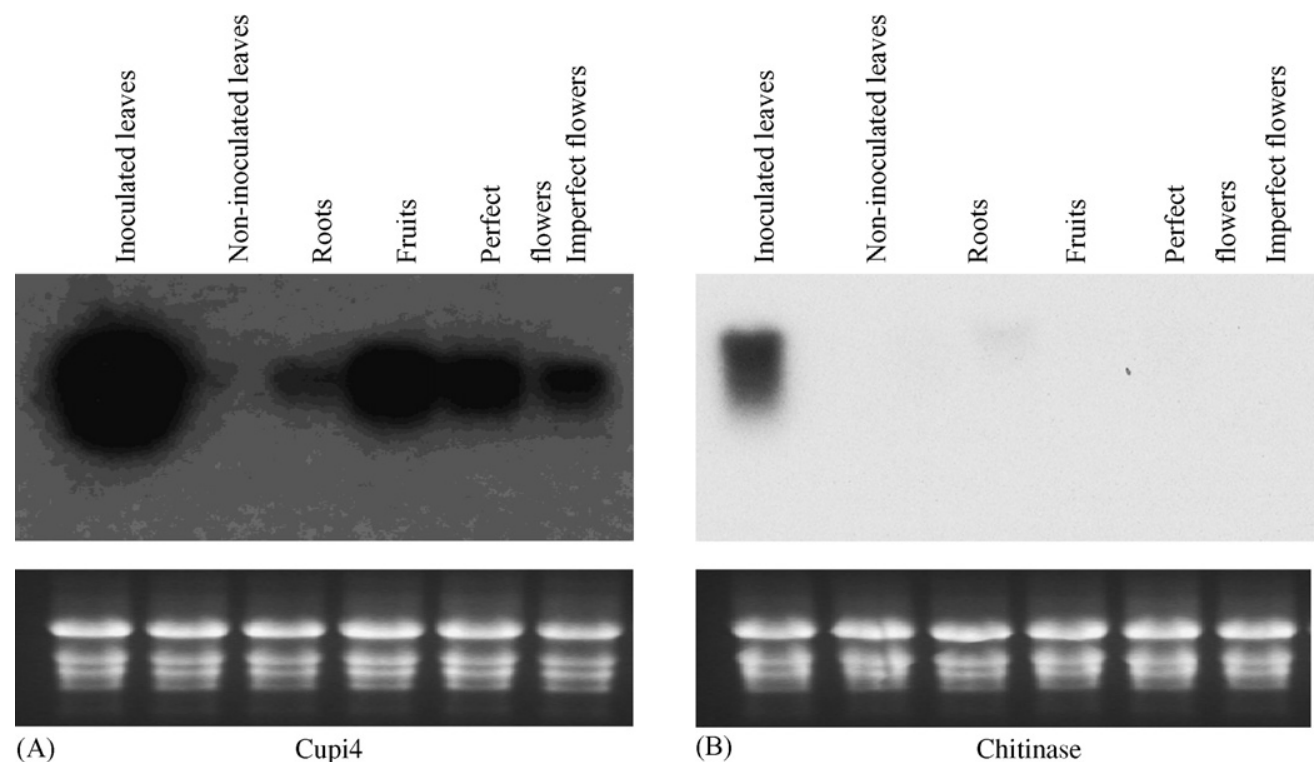

Fig. 7. Northern blot analysis of Cupi4 (A) and cucumber class III chitinase (B) transcripts in different plant tissues. Total RNA was extracted from leaves inoculated with $P$. s. lachrymans, non-inoculated leaves, roots from plants grown in vitro, fruits, imperfect flowers and perfect flowers. Each lane contains $10 \mu \mathrm{g}$ of RNA. Ethidium bromide staining served as control for an equal loading.

bacteria carrying a control plasmid, pQE30 (data not shown). The purification of 6xHis-Cupi4 was performed though a nickel-nitrilotriacetic acid (Ni-NTA) column (Qiagen, CA). Samples were denatured and subjected to electrophoresis $(90$ $125 \mathrm{~V}$ for $1-1.5 \mathrm{~h}$ ) on a $20 \%$ polyacrylamide gel in the presence of SDS followed by Coomassie staining [32]. The expected product of mature CUPI4 (7391 Da) was not detected (data not shown). This data indicated that CUPI4 might be toxic to bacterial host cells.

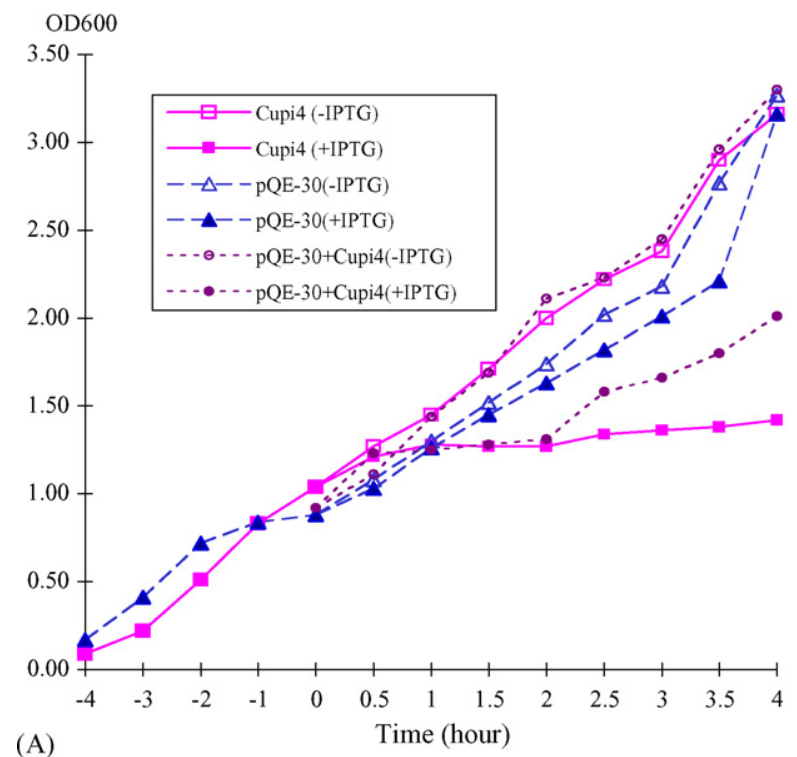

\subsection{Effect of CUPI4 on the growth of E. coli host cells}

The result above indicated that the protein product from the expression of Cupi4 cDNA might be toxic to the E. coli strains used in this experiment. To further clarify the toxicity of CUPI4, E.coli strains carrying pQE30 or pQE30-Cupi4 were cultured separately as described above. When the absorbance at $600 \mathrm{~nm}$ for each culture reached $0.5-0.7$, the cultures with pQE30 and pQE30-Cupi4 were mixed and allowed to continue

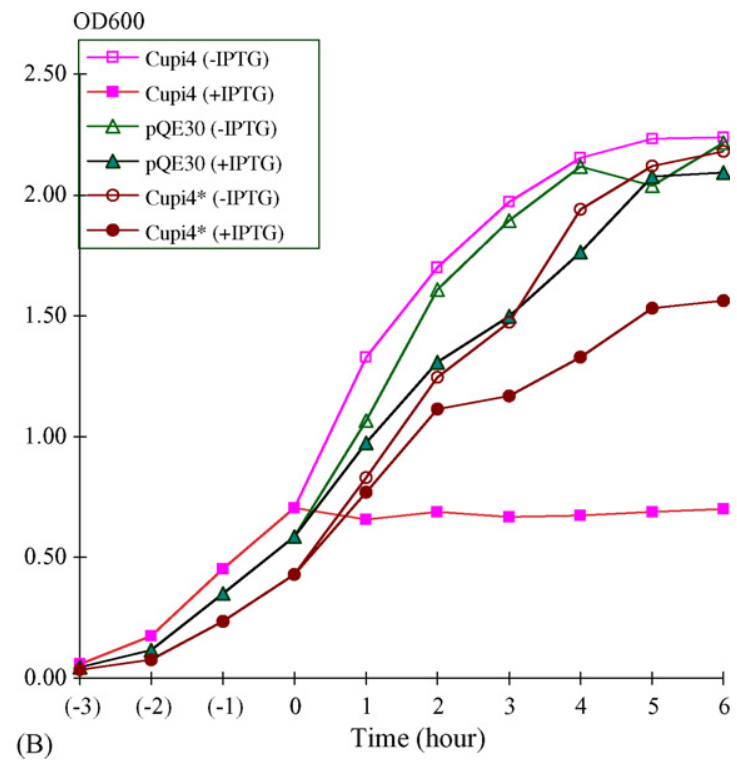

Fig. 8. Effect of CUPI4 on the growth of E. coli in LB medium. Growth curves were obtained by measuring the optical density at $600 \mathrm{~nm}$. Protein expression was induced with $1 \mathrm{mM}$ IPTG at time zero, $-\mathrm{IPTG}=$ no IPTG added, $+\mathrm{IPTG}=1 \mathrm{mM}$ IPTG added. (A) Growth curves of mixed cultures of $E$. coli in the presence (closed symbols) or absence (open symbols) of IPTG. Plasmid symbols are as follow; Cupi4 $=$ pQE30-Cupi4, pQE-30 = control plasmid with no insert, pQE30 + Cupi4 $=$ mixed culture of pQE-30 and pQE30-Cupi4. (B) Growth curves of individual cultures of E. coli in the presence (closed symbols) or absence (open symbols) of IPTG. Plasmid symbols are as follow; Cupi4 = pQE30-Cupi4, pQE-30 = control plasmid with no insert and Cupi4* = pQE30-modified-Cupi4*, with premature stop codon at amino acid position eight. 
to grow for an additional $30 \mathrm{~min}$, followed by an induction with $1 \mathrm{mM}$ IPTG. Each individual culture was served as control. The growth rate of the individual and mixed cultures was measured every $30 \mathrm{~min}$ for $4 \mathrm{~h}$ before and after induction (Fig. 8A). The growth of bacteria carrying plasmid pQE30 alone increased similarly in both induced and non-induced cultures. The growth of bacteria carrying plasmid pQE30-Cupi4 alone slowed and then stopped within the first hour after induction $\left(\mathrm{OD}_{600}=1.28\right)$ compared to the non-induced culture $\left(\mathrm{OD}_{600}=1.45\right)$. In the mixed culture of bacteria carrying plasmids pQE30 and pQE30Cupi4 (pQE30 + pQE30-Cupi4), the growth of the bacteria slowed for the first hour after induction with the $\mathrm{OD}_{600}$ of 1.25 compared to the non-induced-culture $\left(\mathrm{OD}_{600}=1.69\right)$. However, in this same culture, growth of bacteria started to increase again slowly after $2.5 \mathrm{~h}\left(\mathrm{OD}_{600}=1.31\right)$ to $4 \mathrm{~h}\left(\mathrm{OD}_{600}=2.25\right)$. This result indicated that CUPI4 might be toxic to the host cells and it is probably an unstable protein. An alternative explanation is that the growth of bacteria resistant to CUPI4 took over after $2.5 \mathrm{~h}$ or the bacteria carrying pQE30-Cupi4 were all killed, hence no CUPI4 was produced. It should be noted, however that the resumption of growth in the mixed culture was much slower than growth from the individual cultures.

Additional evidence demonstrating the toxicity of CUPI4 to the host cells was obtained from a comparison of the growth of bacteria carrying plasmid pQE30, pQE30-Cupi4 or pQE30modified-Cupi ${ }^{*}$. The latest construct has a stop codon inserted at the eighth amino acid, 6XHGSRPYYLSEN* (Cupi4 sequence is underlined). The bacteria were grown separately, as described above. The growth of bacteria carrying plasmids pQE30 and pQE30-modified-Cupi4* increased similarly in both induced and non-induced cultures, while bacteria carrying plasmid pQE30-Cupi4 slowed and stopped after the first hour after induction $\left(\mathrm{OD}_{600}=0.66\right)$ compared to the non-induced culture $\left(\mathrm{OD}_{600}=1.33\right.$, Fig. 8B $)$.

\section{Discussion}

mRNA differential display was performed to isolate genes whose expression is induced in cucumber tissues expressing SAR after a first inoculation with $P$. s. lachrymans. Fourteen pathogen-induced mRNAs were detected. Marro [29] has shown that the partial sequence of a cDNA called Did-2 was identical to cucumber class III chitinase, CUSCHI [21]. This chitinase is induced after inoculation with different pathogens as well as the chemical inducers of SAR, SA, INA or BTH $[8,23,28]$. The isolation of the chitinase cDNA indicates that the differential display is an appropriate method to isolate genes that are induced during SAR because the level of chitinase is extremely low in non-infected leaves and increases strongly (60-2000-fold) in infected leaves [18]. Four cDNAs called Did3, Did-5, Did-6 and Did-7 were identical to a cucumber ethylene-induced peroxidase, CuPer 2 [36]. Wounding or infection by several pathogens can lead to ethylene production and can induce some PR proteins such as glucanase and chitinase (reviewed in [44]). It is possible that $P$. s. lachrymans induced CuPer2 expression via the production of ethylene either by the plant or the bacteria. Did- 8 was $66 \%$ identical to the Arabidopsis peroxidase, prxr5 [37]. The others, Did-1, Did4, Did-9, Did-10, Did-11, Did-12, Did-13 and Did-14 did not share any significant similarity with any known sequences in databases using BLAST programs. The partial cDNA Did-4 was chosen for further characterization because it was strongly expressed and exhibited a unique hybridization pattern on the RNA gel blot. The analysis of Did-1 is reported elsewhere [29].

A 649-bp long cDNA, CuPi4, corresponding to the Did-4 fragment was isolated, sequenced and analyzed. This cDNA is called Cupi4. It contains an open reading frame of 87 amino acids with a polyadenylation site (AAUAAA) 36 bp downstream from the stop codon in the $3^{\prime}$-untranslated region. No poly (A) tail is present, possibly because of an artifact in cDNA synthesis or the instability of the mRNA during the library construction $[38,45]$. The sequence analysis of Cupi4 showed that it contains a putative signal peptide and might be targeted either to the vacuole $(83 \%)$ or outside the cells $(82 \%)$. The sequence of CUPI4 is rich in proline (19.31\%), leucine $(14.77 \%)$, and lysine $(10.22 \%)$ residues. It is not known whether the proline residues are hydroxylated in the mature protein. At the translated amino acid level, CUPI4 showed homology to two pathogen-inducible proteins; pMB57-10 G 5', from canola (B. napus) [41] and CXc750/ECS1 from Arabidopsis [42,43]. The function of these two proteins is unknown. The expression of the pMB57-10G 5' and of the CXc750/ECS1 genes was induced by Leptosphaeria maculans and Xanthomonas campestris pv. campestris, respectively. The three proteins share several characters, such as encode small basic proline-rich proteins with potential signal peptide and are predicted to enter the secretory pathway. In addition, $C X c 750 /$ ECS1 mRNA transcripts were only detected in ecotypes which showed a resistant phenotype against $X$. c. campestris race 750 . However, overexpression of CXc750/ECS1 in X. c. campestris race 750 -sensitive ecotype did not lead to resistance against $X$. c. campestris race 750 suggesting that $C X c 750 / E C S 1$ is not a resistance gene. Subcellular localization of the CXc750/ECS1 protein indicates that it is associated with the plant cell wall [42]. In humans, it has been reported that small proline-rich proteins are increased when there is damage in genomic DNA and during keratinocyte development. Keratinocytes are found in the human epidermis and function in protecting the skin from the damaging effect of external agents, such as ultraviolet (UV) light [46]. CUPI4 protein might be a reinforcing cell wall compound or have an antimicrobial activity.

Interestingly, Cupi4 transcripts accumulated more rapidly than chitinase transcripts in first leaves inoculated with $P$. $s$. lachrymans but their accumulation occurred simultaneously in systemic second leaves. The expression of Cupi4 both in inoculated first leaves and in systemic non-inoculated second leaves of cucumber plants inoculated on the first leaves with $P$. s. lachrymans and after inoculation with several other pathogens suggests that Cupi4 is associated with SAR.

Inoculation of plants with pathogens provokes the accumulation of SA, JA or ethylene, suggesting their roles as signaling compounds that leads to SAR [47-51]. In cucumber, SA mediated SAR has been reported [52-54]. Exogenous application of BTH leads to induced resistance against Cladosporium 
cucumerinum, moreover, chitinase accumulates more rapidly in plants treated with BTH than in plants treated with SA or water [28]. Similar results were observed in this study; Cupi4 and cucumber class III chitinase transcripts levels, were higher in cucumber plants treated with BTH than in plants treated with SA or INA. The induction of Cupi4 transcripts in cucumber plants treated with SA, INA or BTH suggests that Cupi4 functions in SAR via a SA-dependent pathway. Cupi4 was constitutively expressed in fruits, imperfect flowers, perfect flowers and in vitro grown roots, suggesting a potential role of CUPI4 protein during cucumber development. The expression of Cupi4 in leaves was detected only when plants were inoculated with pathogens as expected, corresponding to the fact that cucumber leaves are more susceptible to infection than the other part of the plants. Overexpression of the CUPI4 in bacteria was attempted, but the protein product seems to be toxic to the host cells even when several conditions were performed. These included three different $E$. coli host strains, two different temperatures (30 and $37^{\circ} \mathrm{C}$ ) for bacterial culture and decreased concentration of IPTG from 1 to $0.5 \mathrm{mM}$. In any cases, we were not able to detect His/CUPI4. While, the role of Cupi4 in SAR is still not clear and needs to be characterized, this present study clearly shows that $\mathrm{CuPi4}$ is a novel SAR gene in cucumber plant.

\section{Acknowledgements}

We thank Dr. Ray Hammerschmidt (Department of Botany and Plant Pathology, Michigan State University, USA) for the cucumber cDNA library. We appreciate helps from our colleagues at the University of Fribourg, especially Dr. Michel Schneider for helping with lab techniques. We thank Drs. Paul Morris, Ray Larsen and Scott Rogers of Bowling Green State University for reading the manuscript, anonymous reviewers and editors who gave helpful suggestions. This work was supported by a fellowship from the Swiss Federal Scholarship Commission to V.P. and grants from the Swiss National Foundation for Scientific Research to J.P.M. (SNF 3100A0104224/1) and to L.S. (No. 31-39595.93).

\section{References}

[1] W.E. Durrant, X. Dong, Systemic acquired resistance, Annu. Rev. Phytopathol. 42 (2004) 185-209.

[2] V. Phuntumart, Transgenic plants for disease resistance, in: C.N. Stewart (Ed.), Transgenic Plants: Current Innovations and Future Trends, Horizon Scientific Press, Wymondmam, UK, 2003, pp. 180-215.

[3] J.P. Métraux, C. Nawrath, T. Genoud, Systemic acquired resistance, Euphytica 124 (2002) 237-243.

[4] L. Sticher, B. Mauch-Mani, J.P. Métraux, Systemic acquired resistance, Annu. Rev. Phytopathol. 35 (1997) 235-270.

[5] S.H. Spoel, A. Koornneef, S.M. Claessens, J.P. Korzelius, J.A. Van Pelt, M.J. Mueller, A.J. Buchala, J.P. Metraux, R. Brown, K. Kazan, L.C. Van Loon, X. Dong, C.M. Pieterse, NPRImodulates cross-talk between salicylate- and jasmonate-dependent defense pathways through a novel function in the cytosol, Plant Cell 15 (2003) 760-770.

[6] T. Genoud, M.B. Trevino Santa Cruz, J.P. Metraux, Numeric simulation of plant signaling networks, Plant Physiol. 126 (4) (2001) 1430-1437.

[7] S.C. Saskia, C.M. van Wees, E.A. de Swart, J.A. van Pelt, L.C. van Loon, C.M. Pieterse, Enhancement of induced disease resistance by simultaneous activation of salicylate- and jasmonate-dependent defense pathways in Arabidopsis thaliana, Proc. Natl. Acad. Sci. U.S.A. 97 (2000) 87118716.

[8] K.A. Lawton, L. Friedrich, M. Hunt, K. Weymann, T. Delaney, H. Kessmann, T. Staub, J. Ryals, Benzothiadiazole induces disease resistance in Arabidopsis by activation of the systemic acquired resistance signal transduction pathway, Plant J. 10 (1996) 71-82.

[9] J. Shah, F. Tsui, D.F. Klessig, Characterization of a salicylic acidinsensitive mutant (sail) of Arabidopsis thaliana, identified in a selective screen utilizing the SA-inducible expression of the tms 2 gene, Mol. PlantMicrobe Interact. 10 (1997) 69-78.

[10] A. Stintzi, T. Heitz, V. Prasad, S. Wiedemann-Merdinoglu, S. Kauffmann, P. Geoffroy, M. Legrand, B. Fritig, Plant "pathogenesis-related" proteins and their role in defense against pathogens, Biochemie 75 (1993) 687706.

[11] R. White, Acetyl salicylic acid (aspirin) induces resistance to tobacco mosaic virus in tobacco, Virology 99 (1979) 410-412.

[12] J. Görlach, S. Volrath, G. Knauf-Beiter, G. Hengy, U. Beckhove, K.H. Kogel, M. Oostendorp, T. Staub, E. Ward, H. Kessmann, J. Ryals, Benzothiadiazole, a novel class of inducers of systemic acquired resistance, activates gene expression and disease resistance in wheat, Plant Cell 8 (1996) 629-643.

[13] J.P. Métraux, P. Ahl Goy, T. Staub, J. Speich, A. Steinmann, J. Ryals, E. Ward, Induced systemic resistance in cucumber in response to 2,6dichloro-isonicotinic acid and pathogens, Adv. Mol. Genet. Plant-Microbe Interact. (1991) 432-439.

[14] E.R. Ward, S.J. Uknes, S.C. Williams, S.S. Dincher, D.L. Wiederhold, D.C. Alexander, P. Ahl-Goy, J.P. Métraux, J.A. Ryals, Coordinate gene activity in response to agents that induce systemic acquired resistance, Plant Cell 3 (1991) 1085-1094.

[15] J. Smith-Becker, E. Marois, E.J. Huguet, S.L. Midland, J.J. Sims, N.T. Keen, Accumulation of salicylic acid and 4-hydroxybenzoic acid in phloem fluids of cucumber during systemic acquired resistance is preceded by a transient increase in phenylalanine ammonia-lyase activity in petioles and stems, Plant Physiol. 116 (1998) 231-238.

[16] S. Schneider, W.R. Ullrich, Differential induction of resistance and enhanced enzyme activities in cucumber and tobacco caused by treatment with various abiotic and biotic inducers, Physiol. Mol. Plant Pathol. 45 (1994) 291-304.

[17] J. Siegrist, W. Jeblick, H. Kauss, Defense responses in infected and elicited cucumber (Cucumis sativus L.) hypocotyl segments exhibiting acquired resistance, Plant Physiol. 105 (1994) 1365-1374.

[18] J.P. Métraux, T. Boller, Local and systemic induction of chitinase in cucumber plants in response to viral, bacterial and fungal infections, Physiol. Mol. Plant Pathol. 28 (1986) 161-169.

[19] R. Hammerschmidt, E. Nuckles, J. Kuc, Association of enhanced peroxidase activity with induced systemic resistance of cucumber to Colletotrichum lagenarium, Physiol. Plant Pathol. 20 (1982) 73-82.

[20] I. Feussner, I.G. Fritz, B. Hause, W.R. Ullrich, C. Wasternack, Induction of a new lipoxygenase form in cucumber leaves by salicylic acid or 2,6dichloroisonicotinic acid, Bot. Acta 110 (1996) 101-108.

[21] J. Kuc, S. Richmond, Aspects of the protection of cucumber against Colletotrichum lagenarium by Colletotrichum lagenarium, Phytopathology 67 (1977) 533-536.

[22] T. Boller, J.P. Métraux, Extracellular localization of chitinase in cucumber, Physiol. Mol. Plant Pathol. 33 (1988) 11-16.

[23] J.P. Métraux, W. Burkardt, M. Moyer, S. Dichner, W. Middlesteadt, S. Pzyne, M. Carnes, J. Ryals, Isolation of a complementary DNA encoding a chitinase with structural homology to a bifunctional lysozyme/chitinase, Proc. Natl. Acad. Sci. U.S.A. 86 (1989) 896-900.

[24] S.A. Avdiushko, X.S. Ye, D.F. Hildebrand, J. Kuc, Induction of lipoxygenase activity in immunized cucumber plants, Physiol. Mol. Plant Pathol. 42 (1993) 83-95.

[25] C. Ji, J. Kuc, Purification and characterization of an acidic $\beta$-1,3-glucanase from cucumber and its relationship to systemic disease resistance induced by Colletotrichum lagenarium and tobacco necrosis virus, Mol. Plant-Microbe Interact. 8 (1995) 899-905.

[26] J.B. Rasmussen, J.A. Smith, S. Williams, W. Burkhart, E. Ward, S.C. Somerville, J. Ryals, R. Hammerschmidt, cDNA cloning and systemic 
expression of acidic peroxidases associated with systemic acquired resistance to disease in cucumber, Physiol. Mol. Plant Pathol. 46 (1995) 389_ 400 .

[27] K.A. Lawton, J. Beck, S. Potter, E. Ward, J. Ryals, Regulation of cucumber class III chitinase gene expression, Mol. Plant-Microbe Interact. 7 (1994) 48-57.

[28] Y. Narusaka, M. Narusaka, T. Horio, H. Ishii, Comparison of local and systemic induction of acquired disease resistance in cucumber plants treated with benzothiadiazoles or salicylic acid, Plant Cell Physiol. 40 (1999) 388-395.

[29] P. Marro, Isolation of a novel cucumber cDNA associated with systemic acquired resistance by differential display of mRNA, in: P. Marro, Bases moléculaires de la résistance induite chez le concombre (Cucumis sativus L.) (Thèse) No. 1185, Biologie végétale, Université de Fribourg, Fribourg, 1997, pp. 55-76.

[30] P. Liang, L. Averboukh, A.B. Pardee, Distribution and cloning of eukaryotic mRNAs by means of differential display: refinements and optimization, Nucl. Acid Res. 21 (1993) 3269-3275.

[31] P. Liang, A.B. Pardee, Differential display of eukaryotic messenger RNA by means of the polymerase chain reaction, Science 257 (1992) 967-971.

[32] J. Sambrook, E.F. Fritsch, T. Maniatis, Molecular cloning, in: J. Sambrook, E.F. Fritsch, T. Maniatis (Eds.), A laboratory manual, NY Cold Spring Harbor Laboratory, Cold Spring Harbor, 1989, pp. 7.43-7.50.

[33] J.M. Short, J.M. Fernandez, J.A. Sorge, W.D. Huse, Lambda ZAP: a bacteriophage lambda expression vector with in vivo excision properties, Nucl. Acids Res. 16 (1988) 7583-7600.

[34] S.O. Rogers, A.J. Bendich, Extraction of DNA from plant tissues, in: S.O. Rogers, A.J. Bendich (Eds.), Plant Molecular Biology Manual A6, Kluwer Academic Publishers, Belgium, 1988, pp. 1-10.

[35] S.F. Altschul, W. Gish, W. Miller, E.W. Myers, D.J. Lipman, Basic local alignment search tool, J. Mol. Biol. 215 (1990) 403-410.

[36] P.H. Morgens, A.M. Callahan, L.J. Dunn, F.B. Abeles, Isolation and sequencing of cDNA clones encoding ethylene-induced putative peroxidases from cucumber cotyledons, Plant Mol. Biol. 14 (1990) 715725.

[37] N. Capelli, M. Tognolli, J. Flach, S. Overney, C. Penel, H. Greppin, P. Simon, Eleven cDNA clones from Arabidopsis thaliana encoding isoperoxidases (accession nos. X98313, X98314, X98315, X98316, X98317, X98318, X98319, X98320, X98321, X98322 and X98323), Plant Physiol. 112 (1996) 446.

[38] L. Wu, T. Ueda, J. Messing, The formation of mRNA $3^{\prime}$-ends in plants, Plant J. 8 (1995) 323-329.

[39] J.D. Bendtsen, H. Nielsen, G. Heijne, S. Brunak, Improved prediction of signal peptides: SignalP 3.0, J. Mol. Biol. 340 (2004) 783-795.

[40] J.D. Thompson, D.G. Higgins, T.J. Gibson, CLUSTAL W: improving the sensitivity of progressive multiple sequence alignment through sequence weighting, position-specific gap penalties and weight matrix choice, Nucl. Acids Res. 22 (1994) 4673-4680.

[41] B. Fristensky, M. Balcerzak, F.D. He, P. Zhang, Expressed sequence tags from the defense response of Brassica napus to Leptosphaeria maculans. On line Mol. Plant Pathol. (1999).

[42] W. Aufsatz, D. Amry, C. Grimm, The ECS1 gene of Arabidopsis encodes a plant cell wall-associated protein and is potentially linked to a locus influencing resistance to Xanthomonas campestris, Plant Mol. Biol. 38 (1998) 965-976.

[43] W. Aufsatz, C. Grimm, A new, pathogen-inducible gene of Arabidopsis is expressed in an ecotype-specific manner, Plant Mol. Biol. 25 (1994) 229239.

[44] T. Boller, Ethylene and plant-pathogen interactions, in: H.E. Flores, R.N. Arteca, J.C. Shannon (Eds.), Polyamines and ethylene: Biochemistry, Physiology, and Interaction, Pennsylvania: Current Topics in Plant Physiology, 1990, pp. 138-145.

[45] J.L. Manley, Messenger RNA polydenylylation: a universal modification, Proc. Natl. Acad. Sci. U.S.A. 92 (1995) 1800-1801.

[46] S. Gibbs, F. Lohman, W. Teubel, P. Vandeputte, C. Backendorf, Characterization of the human spr2 promoter-induction after UV irradiation or TPA treatment and regulation during differentiation of cultured primary keratinocytes, Nucl. Acids Res. 18 (1990) 4401-4407.

[47] T. Boller, Ethylene in pathogenesis and disease resistance, in: A.K. Mattoo, J.C. Suttle (Eds.), The Plant Hormone Ethylene, CRC Press, Boca Raton, FL, 1991, pp. 293-314.

[48] Y. Cohen, U. Gisi, T. Niderman, Local and systemic protection against Phytophthora infestans induced in potato and tomato plants by jasmonic acid and jasmonic methyl ester, Phytopathology 83 (1993) 1054-1062.

[49] P. Reymond, E.E. Farmer, Jasmonate, salicylate as global signals for defense gene expression, Curr. Opin. Plant Biol. 1 (1998) 404-411.

[50] J. Malamy, J.P. Carr, D.F. Klessig, I. Raskin, Salicylic acid - a likely endogenous signal in the resistance response of tobacco to viral infection, Science 250 (1990) 1002-1004.

[51] J.P. Métraux, H. Signer, J. Ryals, E. Ward, M. Wyss-Benz, J. Gaudin, K. Raschdorf, E. Schmid, W. Blum, B. Inverardi, Increase in salicylic acid at the onset of systemic acquired resistance in cucumber, Science 250 (1990) 1004-1006.

[52] J.B. Rasmussen, R. Hammerschmidt, M.N. Zook, Systemic induction of salicylic acid accumulation in cucumber after inoculation with Pseudomonas syringae pv. syringae, Plant Physiol. 97 (1991) 1342-1347.

[53] N. Benhamou, R.R. Belanger, Induction of systemic resistance to Pythium damping-off in cucumber plants by benzothiadiazole: ultrastructure and cytochemistry of the host response, Plant J. 14 (1998) 13-21.

[54] W. Mölders, A. Buchala, J.P. Metraux, Transport of salicylic acid in tobacco necrosis virus-infected cucumber plants, Plant Physiol. 112 (1996) 787-792. 